\title{
Interrupting Short-Circuit Direct Current Using an AC Circuit Breaker in Series with a Reactor
}

\author{
Saurabh Kulkarni and Surya Santoso \\ Department of Electrical and Computer Engineering, University of Texas at Austin, Austin, TX 78712, USA \\ Correspondence should be addressed to Saurabh Kulkarni, saurabh86.k@gmail.com
}

Received 31 July 2012; Accepted 16 August 2012

Academic Editor: Qingmin Li

Copyright (๑) 2012 S. Kulkarni and S. Santoso. This is an open access article distributed under the Creative Commons Attribution License, which permits unrestricted use, distribution, and reproduction in any medium, provided the original work is properly cited.

\begin{abstract}
This paper describes and demonstrates the principle and efficacy of a novel direct current fault interruption scheme using a reactor in series with a controlled rectifier and a conventional AC circuit breaker. The presence of the series reactor limits the capacitive discharge current from the DC filter capacitor at the output terminals of the phase-controlled rectifier. In addition, the series reactor along with the filter capacitor forms an underdamped series RLC circuit which forces the fault current to oscillate about zero. This synthetic alternating current can then be interrupted using a conventional AC circuit breaker. The selection criteria for the series reactor and overcurrent protection are presented as well. Using the proposed scheme for an example case, a DC fault current magnitude is reduced from $56 \mathrm{kA}$ to $14 \mathrm{kA}$, while the interruption time is reduced from $44 \mathrm{~ms}$ to $25 \mathrm{~ms}$.
\end{abstract}

\section{Introduction}

Medium voltage DC or MVDC system architectures are being considered in distribution systems of electric ships as well as electric vehicles $[1,2]$. Such systems are generally fed by phase-controlled rectifiers or simply controlled rectifiers. They are constructed using thyristors as the switch element in the bridge. The firing pulses of the thyristors can be controlled to change the DC voltage at the output terminals of the rectifier. However, a fault at the terminals of a controlled rectifier results in a large magnitude fault current. Without current zero crossings, clearing such faults is challenging. Furthermore, for faults with low fault resistance (or even bolted faults) the transient DC fault current has a high magnitude impulse component with a very short rise time. This can have detrimental effects on the equipment. Existing and proposed techniques for interrupting DC fault current utilize electromechanical interrupters, solid-state switches, and combinations of both technologies $[2,3]$. In order to utilize electromechanical circuit breakers (EMCBs) in DC systems, it is proposed to generate artificial current zeros in the arc by superimposing a counter flow of current, typically from an oscillating circuit evoked only during circuit breaking. On the other hand, solid-state circuit breakers (SSCBs) make use of power electronic switches for interrupting the current without arcing [4-6]. Disadvantages of SSCBs include the absence of galvanic isolation and generally lack of the same withstand against transient overvoltages. Power semiconductor switches have high conduction losses due to on-state resistance and forward voltage drop discouraging their use. Even though this type of circuit breaker allows for very high interruption speeds, existing protection methods implemented on protection relays typically do not utilize this attractive feature [7]. Solid-state breakers are commercially available only for low power applications. Hybrid circuit breakers make use of a combination of both electromechanical parts and power electronic switches for current interruption at high speeds [8]. They combine the advantages of both technologies [4]. Just like SSCBs, hybrid breakers are still in the research and development stage. In [9] relays associated with converters are used to detect and clear faults in a DC distribution system. The method proposed in [10] uses AC circuit breakers on the AC side of the rectifier to coordinate with the DC switches to isolate the faulted section in a multiterminal DC system. An introduction to DC fault interruption is given in Section 2, while an overview of interruption techniques is provided in Section 3. 
TABLE 1: Means of interrupting DC faults.

\begin{tabular}{|c|c|c|}
\hline Method & $\begin{array}{c}\text { Commercial } \\
\text { technology } \\
\text { available }\end{array}$ & Technical challenges \\
\hline $\begin{array}{l}\text { On AC side by means of } \\
\text { conventional AC circuit } \\
\text { breakers }\end{array}$ & Yes & $\begin{array}{l}\text { Large and prolonged } \\
\text { fault currents due to } \\
\text { several AC cycle } \\
\text { interruption times. } \\
\text { Overrating necessary for } \\
\text { generator frequencies } \\
\text { above } 60 \mathrm{~Hz}\end{array}$ \\
\hline $\begin{array}{l}\text { On DC side by means of } \\
\text { electromechanical DC } \\
\text { circuit breakers }\end{array}$ & Yes & $\begin{array}{l}\text { Commercial solutions } \\
\text { limited to less than } \\
4.5 \mathrm{kV} \mathrm{DC}\end{array}$ \\
\hline $\begin{array}{l}\text { On DC side by means of } \\
\text { power electronic switches }\end{array}$ & No & $\begin{array}{l}\text { Additional losses. } \\
\text { Development of } \\
\text { technology necessary }\end{array}$ \\
\hline
\end{tabular}

The objective of this paper is to propose and successfully demonstrate the application of a new DC fault clearing mechanism which is simple, fast, and efficient. Furthermore, the mechanism should limit the fault current magnitude and physically isolate the faulted section from the rest of the system to prevent damage to equipment. To achieve this goal, the paper proposes an innovative DC fault interruption scheme for a controlled rectifier by inserting a series reactor and using a conventional AC circuit breaker for fault clearing. The addition of the reactor causes the rising fault current to oscillate and thus creates zero crossings which are inherently absent from DC systems. A conventional AC circuit breaker can then be employed to interrupt the fault current during the first zero crossing [11]. This approach is developed in Section 4 using an example of a fault at the terminals of a controlled rectifier. This fault also results in a high magnitude current impulse (56 kA in an example case) caused by the filter capacitor discharging into the fault resistance. Section 5 describes the detailed switch and average value circuit models used for validating the proposed approach. Section 6 analyzes the use of firing angle control to bring the fault current down to zero. The current is brought to zero in about $44 \mathrm{~ms}$ from the start of the fault. In Section 7, it is proposed to add an inductor in series with the rectifier output terminals to reduce the peak magnitude of the transient fault current and induce oscillations in the fault current. Section 8 describes how a conventional AC circuit breaker can be used for fault interruption at the first zero crossing $25 \mathrm{~ms}$ after the fault occurs. Additionally, using a series inductor of $1 \mathrm{mH}$ the peak fault current is reduced to $14 \mathrm{kA}$. The fault current interruption time is shown to be greatly reduced to about $9 \mathrm{~ms}$ by using simple current detection scheme for the reactor assisted circuit breaker. A detailed discussion on the selection criteria for the series inductor is given in Section 9. Finally, the conclusion is presented in Section 10.

\section{Principles of DC Fault Interruption}

Broadly speaking, there are three available "methods" of interrupting DC fault currents as given in Table 1. Interrupting $\mathrm{DC}$ faults on the $\mathrm{AC}$ side of a rectifier fed system is
TABLE 2: DC fault behavior of power converters.

\begin{tabular}{lcc}
\hline Technology & $\begin{array}{c}\text { Fault current } \\
\text { breaking } \\
\text { capability }\end{array}$ & $\begin{array}{c}\text { Fault current } \\
\text { limitation } \\
\text { capability }\end{array}$ \\
\hline $\begin{array}{l}\text { Diode rectifiers } \\
\text { Forced commutated "active" } \\
\text { rectifiers using IGBTs, IGCTs, } \\
\text { etc. with free wheeling diodes }\end{array}$ & No & No \\
$\begin{array}{l}\text { Thyristor-controlled rectifiers } \\
\begin{array}{l}\text { Isolated DC-DC converters } \\
\text { with HF transformer }\end{array}\end{array}$ & $\begin{array}{r}\text { At first AC side } \\
\text { current zero } \\
\text { Within one HF } \\
\text { half cycle }\end{array}$ & No \\
\hline
\end{tabular}

possible; however, it entails overrating all the equipment a longer fault clearing time. Short-circuit faults on the DC side can be interrupted by either using electromechanical breakers or power electronic switches. Power electronic switches in the converters themselves can also be used to bring down and interrupt the DC fault current. Table 2 lists the current state-of-the-art regarding power conversion technologies and their associated characteristics under MVDC bus fault conditions.

Except for isolated DC-DC converters, the magnitude of DC fault currents associated with all the common power conversion technologies listed in Table 1 is governed by the combined effect of the AC and DC side impedances. In addition, DC link capacitances may contribute additional, significantly large, transient fault current injections as they discharge during a DC fault event.

The general classification of DC fault interruption methods based on various criteria is shown in Figure 1. The various principles used for classification are explained in detail in Section 3.

\section{Existing Methods of DC Fault Interruption}

Current interruption in a power system depends upon the source, load, and the energy storage elements in the network. When a fault occurs in the network, the energy supplied by the source will be dumped into the resistors and the inductors along the path of the fault current, while the capacitors will give out some energy proportional to the voltage reduction in the network. Equation (1) is obtained from basic circuit analysis.

$$
I_{\text {fault }}=\frac{V_{s}}{Z} .
$$

Based on the formula, two methods for fault current control are evident. The first method controls the source voltage $V_{s}$ and the other controls the line impedance to the fault, $Z$. Based on these two principles, current interruption is broadly classified into "source potential reduction" and "switch assisted interruption", shown in Figure 1. These methods are described below.

3.1. Source Potential Reduction. In this method, the source voltage is designed to be externally controllable. On sensing 


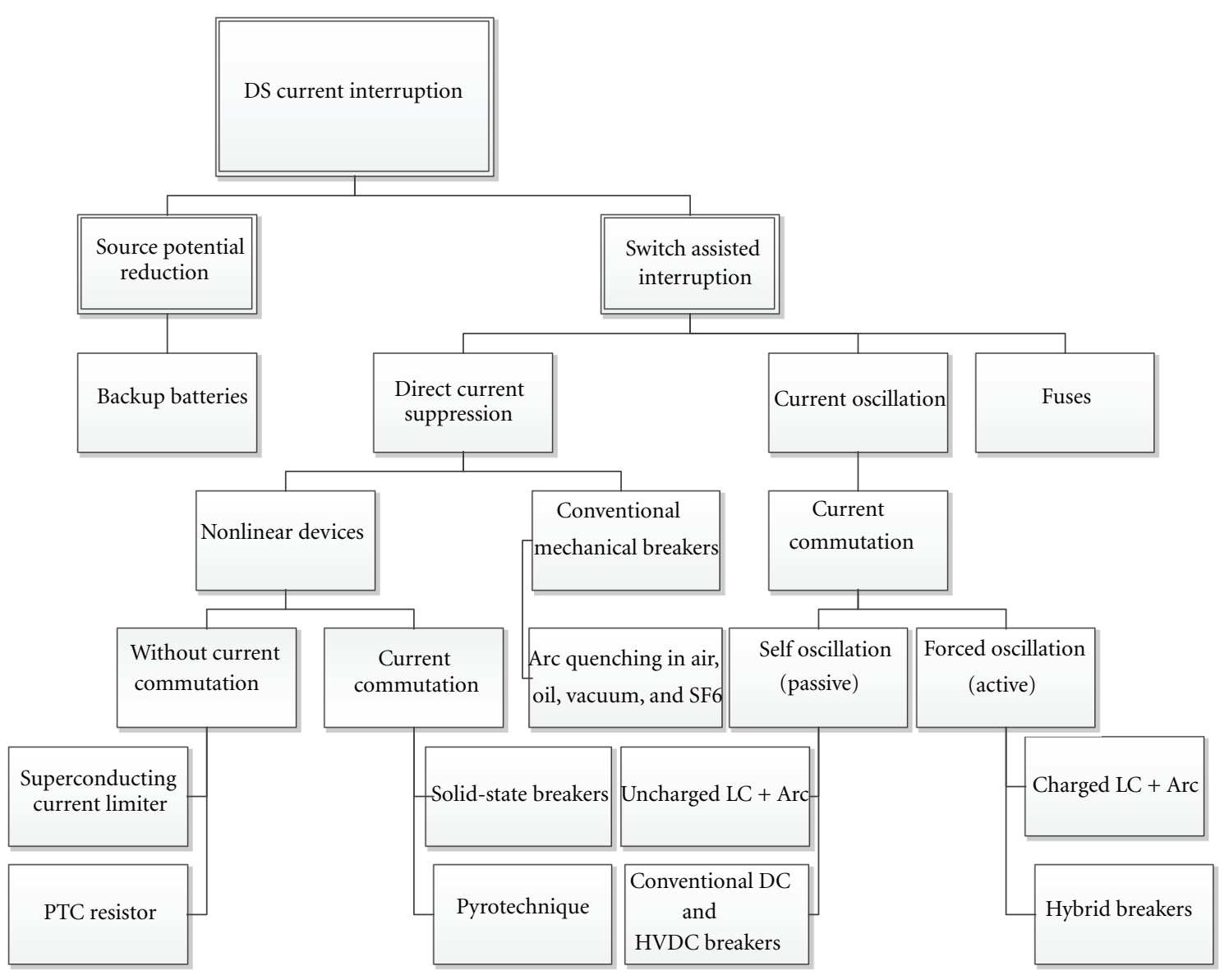

FIgURE 1: Classification of DC fault interruption methods.

an increase in the network current, the source voltage can be gradually brought to zero, thereby reducing the fault current. However, reducing the source voltage can cause a systemwide power outage, during a remote fault. The customers who have sensitive loads might seek to install backup supplies at their ends. Figure 2 shows the schematic for this method. Source control method can be used in small DC networks which use controlled static AC-DC converters.

The second method of fault current interruption involves creating a physical open gap in the conductor carrying the current. The second method is examined in the following sections. Existing and newly proposed techniques utilize electromechanical interrupters, solid-state switches, and combinations of both to interrupt direct currents. Apart from these methods some of the new methods that are still in research are also examined.

3.2. Switch Assisted Interruption. In this method, the source voltage is held constant and the impedance to the fault (usually the line impedance) is left unmodified at normal currents levels. When a fault occurs, large impedance is introduced in series with the transmission line which suppresses the current and brings it to zero. Modern circuit breakers either use an arc or a nonlinear device for producing the required impedance in the network. These methods utilize the principle of current commutation which is explained

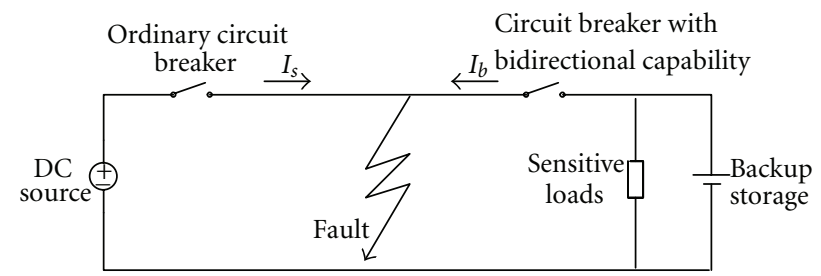

Figure 2: Source voltage control for current interruption.

here briefly. A device using this principle has one element for conducting the continuous current and the other for conducting and stopping the fault current. The element which is used for conducting continuous current has high continuous current rating, low conduction losses, and a low current interruption capability. The other element has opposite properties. Since the conduction and interruption operations occur in separate devices designed for the respective purposes, this method produces a high performance breaker with the lowest size consideration.

Therefore, this current suppression method is known as switch assisted interruption utilizing DC breakers as shown in Figure 2. There are three common interruption methods used in DC breakers. These are direct current suppression, current oscillation, and lastly fuse. These methods are described below. 
3.2.1. Direct Current Suppression. These DC breakers, due to the absence of current zero, are designed to produce a voltage drop equal to the source voltage and withstand the energy dissipation caused by the inductor and the voltage source until the energy from the inductor reduces to zero. Direct current suppression breakers can be further classified as follows.

(a) Conventional Mechanical Breakers. These circuit breakers use conventional arc quenching media like air, oil, vacuum, and SF6. These breakers can also use auxiliaries like puffers, forced blast, and arc chutes for enhancing arc interruption.

(b) Breakers Making Use of Nonlinear Devices with Current Commutation. There are two types of breakers in this category.

(i) Pyrobreakers: Pyrobreakers consist of a solid copper bar, explosive charge, and a fuse [12]. The solid copper strip in the breaker carries the continuous current. The copper bar along with the explosive charge forms the pyrotechnic disconnecter. On receiving a trip command from a relay, the pyrotechnic disconnecter shears the copper bar with the help of the explosive charge and commutates the current to the fuse. The fuse interrupts the current later. This breaker has special applications in rectifier protection on $\mathrm{AC}$ and DC sides.

(ii) Solid-State Breakers: Solid-State Breakers (SSB) are high-speed breakers making use of power thyristors, GTOs, IGBTs, and MOSFETs for current interruption. They make use of power electronic switches alone for interrupting the current with minimum arcing $[13,14]$. SSBs produce a PN junction barrier region during current interruption for impeding the current without any arc. Since the above process does not involve any wear and tear the life of the breaker is theoretically infinite. Since power electronic devices are prone to breakdown at high voltage transients, SSBs are fitted with a series isolation switch for galvanic isolation. Snubber capacitors and surge arresters are fitted in parallel with the breakers for absorbing the voltage and current surges during turn on and turn off periods. SSBs are mostly used as current limiting breakers in those networks where the devices have low short time current ratings [15-18].

Since the semiconductor switches do not have the ability to dissipate the energy stored in the power system, it is connected in parallel with surge arresters, snubbers, and capacitors for absorbing the system energy after current interruption. Any heat produced due to energy loss should be cooled effectively for its successful operation. But this type of circuit breaker does not provide the physical galvanic isolation between either sides of a breaker. It may breakdown if a transient voltage across the contacts is relatively high. Another disadvantage that discourages the use of power semiconductor switches is that their conduction losses are high due to its on-state resistance and forward voltage drop. This energy loss poses an overload limit for the breaker. Even though this type of circuit breaker operates at very high speeds, this attractive feature becomes limited without the availability of high-speed relays. IGBT, GTO, SIT, and IGCT [8] are the most commonly used switches in solid-state circuit breakers. Solidstate breakers remain in the research stage for high power applications. However, commercial solid-state breakers are available for low power applications.

(c) Breakers making use of Nonlinear Devices without Current Commutation. There are two types of breakers in this category.

(i) Positive Temperature Coefficient Breakers: These breakers make use of positive temperature coefficient (PTC) resistors as the current limiting element. The PTC resistors are made of metal filled polymer matrix for carrying the current. Under normal conditions, the heat produced is equal to the heat dissipated such that the filler materials in the matrix cling together. When the current increases, the matrix expands and the filler particles move apart due to heat production and produce almost a step increase in the resistance value $[19,20]$. These PTC materials conduct the entire steady state current under normal conditions.

(ii) Superconducting Current Limiter: Only resistive superconducting current limiters (SCCL) are used for DC interruption [21]. All superconductors have a time dependent critical current value. When the current through the superconductor is lower than the critical current the resistance of the superconductor is zero. The cooling of the superconductors is designed to keep the critical current above the load current, under normal conditions. When a high short-circuit current above the critical value flows through the conductor, the superconductor loses its zero resistance state and gets heated up. This process acts like a positive feedback loop and in a few milliseconds causes a step increase in the superconductors' impedance. This process is used in these breakers for current interruption.

3.2.2. Current Oscillation Based DC Breakers. Usually AC breakers are designed to interrupt currents at inherent current zeros when the arc extinguishes temporarily. These breakers can be used for DC current breaking by fitting an oscillator in parallel with the AC breaker. The oscillator circuit consists of a capacitor in series with an inductor. It can be classified based on the charge stored across the capacitor as follows.

(a) Passive Circuit Oscillator. In this type of circuit breaker, an LC circuit is connected across the circuit breaker contacts before the opening of circuit breaker contacts. When the contacts of a circuit breaker start to move apart, a small 
voltage appears across the arc. This voltage excites the LC circuit into oscillation. The oscillation increases in magnitude with time. Finally at some point in time the current through the oscillator will be equal to the fault current. When this happens, the fault current commutates from the breaker to the LC circuit. The transmission line inductance charges the capacitor to a high voltage.

(b) Using Active Circuit Oscillator. The circuit for active current commutation breaker looks almost similar to the passive circuit, except that the capacitor is always kept fully charged. When the circuit breaker receives a trip command, the contacts are retracted and a counter current is injected through the arcing contacts with the help of the capacitor.

The hybrid circuit breaker falls under this category.

(i) Hybrid Circuit Breaker: Hybrid circuit breakers make use of a combination of both electromechanical parts and power electronic switches for current interruption at high speeds $[18,22]$. They enjoy the advantages of both the solid-state and electromechanical breakers. Thus, this type of circuit breaker makes up a major percentage of high-speed circuit breakers. The main components used in a hybridized circuit breaker are main switch, solid-state switch, and isolation switch. The power electronic switch is connected in parallel with the mechanical switch, while the isolation switch is connected in series with the solid-state switch, as illustrated in Figure 3, [22, 23]. During normal operating conditions the current flows through the mechanical breaker (S). When a fault is detected, breaker $(\mathrm{S})$ opens and the current is commuted to the semiconductor device. As a result, the mechanical part does not need to extinguish the arc. The semiconductor device conducts until breaker (S) is able to fully block the voltage. The stored energy in the line inductance causes fast voltage increase until the varistor conducts. The varistor blocks voltage above the grid voltage and hence the line inductance is demagnetized. Since hybrid breakers are in the research and development stage, they are not yet economical $[18,23]$.

3.2.3. Fuses. They are similar to AC fuses. Once a fuse interrupts a fault current, the fuse link must be replaced.

There are a few commercial DC circuit breakers currently available in the marketplace. They are used in HVDC, DC railway traction, and large DC industrial drive systems. Areva has developed electromechanical circuit breakers based on an artificial zero crossing approach as well [3]. During the interruption process, a simple LC oscillator circuit in parallel with the contacts is excited by the arc voltage into resonance. The oscillating current crosses zero allowing the arc to be extinguished. Other commercially available DC circuit breakers (from General Electric, Secheron, Siemens [24-26]) are rated between $1 \mathrm{kV}$ DC and $5 \mathrm{kV}$ DC with interrupting rating of $40 \mathrm{kA} / 31.5 \mathrm{~ms}$ to $125 \mathrm{kA} / 100 \mathrm{~ms}$ depending on the capacity of the arc chutes.

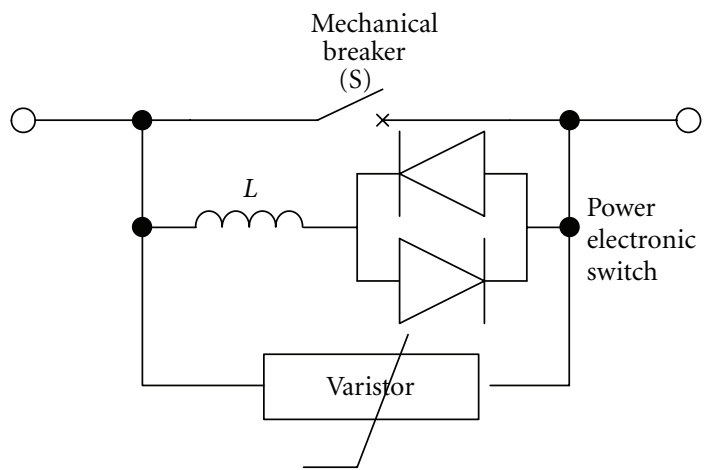

Figure 3: General schematic of hybrid circuit breaker.

Sections 2 and 3 dealt with the challenges and approaches for DC fault interruption. It was pointed out that, unlike AC current, there is no natural current zero for DC currents, which makes fault interruption challenging. Various currently available and proposed DC fault mitigation techniques were discussed. The following section describes an innovated DC fault interruption scheme using a reactor assisted AC circuit breaker.

\section{Principles of DC Fault Interruption Using Reactor Assisted AC Breakers}

A fault on an MVDC system results in a fault current with no zero crossings, making clearing such faults challenging using any traditional interruption techniques. Furthermore, for faults with low fault resistance, the transient DC fault current has a high magnitude impulse and a short rise time. In this section an innovative concept of using a reactor assisted AC circuit breaker to interrupt DC faults is demonstrated using an example case. The addition of the reactor causes the rising fault current to oscillate and have zero crossings which are inherently absent from DC systems. A conventional $\mathrm{AC}$ circuit breaker is then employed to interrupt the fault current.

Consider a simple MVDC system fed by a six-pulse phase-controlled rectifier shown in Figure 4(a). The detailed representation of the rectifier is shown in Figure $4(\mathrm{~b})$. The input of the rectifier is connected to a $4.16 \mathrm{kV}, 60 \mathrm{~Hz}$ threephase AC source, with a $10 \mathrm{kA}$ short-circuit current capacity. The filter inductor $L_{d c}=2.4431 \mu \mathrm{H}$ maintains continuous rectifier current and the filter capacitor $C=8 \mathrm{mF}$ keeps the output DC voltage ripple within $1 \%$. The rectifier supplies an equivalent DC load of $4 \mathrm{MW}$. During normal load conditions, the firing angle of the rectifier $(\alpha)$ is set to $0 \circ$ such that it supplies $5.62 \mathrm{kV}$ to the DC load. At $0.3 \mathrm{~s}$ a fault with a resistance of $0.1 \Omega$ is simulated at the terminals of the rectifier using PSCAD/EMTDC. To get the worst case fault current conditions any series inductance in the path of the fault has been neglected. The fault current and the DC voltage profile are shown in Figure 5.

It can be seen that the fault current rises almost immediately as the result of the filter capacitor discharging into the fault resistance. After the initial impulse subsides, 


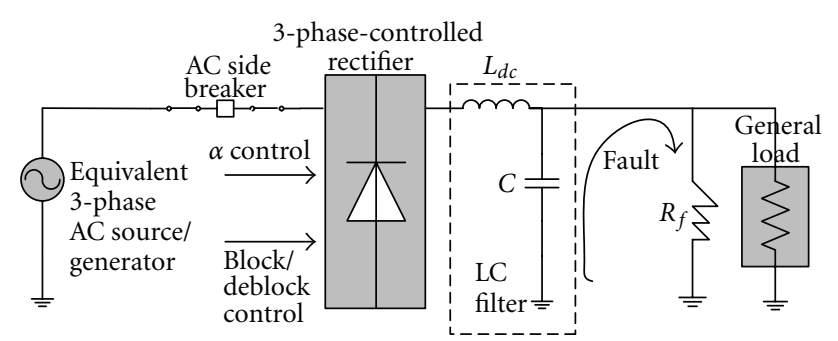

(a) Controlled rectifier with fault at the terminals

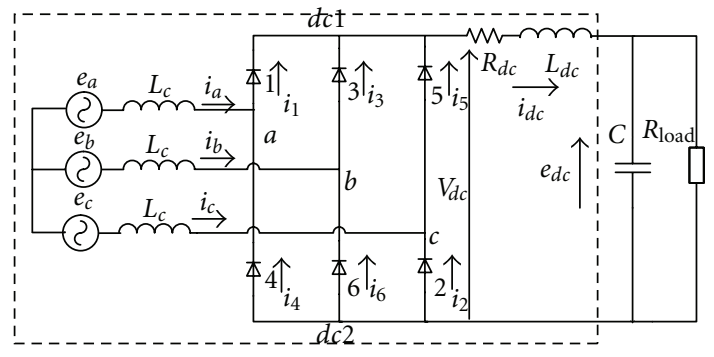

(b) Six-pulse rectifier model with AVM obtained for dashed section

FIgURE 4: MVDC system fed by controlled rectifier.

the current contributed by the rectifier keeps rising till it reaches a steady state value. This case highlights the major challenges in tackling DC faults. Firstly, the high magnitude current impulse can be potentially harmful to the equipment and secondly, the fault current keeps rising without any zero crossings. To bring this fault current to zero the firing angle ( $\alpha$ ) can be set to $90^{\circ}$ or the firing pulses to the rectifier can be blocked. A detailed discussion on this method is given in Section 6. However, this action will not force the fault current to zero immediately. Furthermore, the initial current impulse cannot be prevented by using this method. To overcome the shortcomings of this technique it is proposed in this paper to induce artificial zero crossings in the fault current and utilize a conventional AC circuit breaker to clear the fault. An LC oscillator circuit is needed to induce zero crossings. Since, the filter capacitor is already present, it is proposed in this paper to insert an inductor in series with it. This inductor will serve a dual purpose by also damping the initial fault current impulse. Additionally, the inductor will not alter the performance of the system during normal steady state load conditions. Using an AC circuit breaker for fault clearing will also provide galvanic isolation to the faulted section, which only firing control will be unable to do. The following section provides a description of the rectifier modeling techniques and circuit models used in this paper. Subsequent sections detail the proposed method utilizing these circuit models.

\section{Analytical and Switch Models of Controlled Rectifier}

The detailed model of a six-pulse rectifier system described in the previous section is shown in Figure 4(b). The circuit is composed of an AC source; AC inductance $\left(L_{c}\right)$; thyristors 1,3 , and 5 which form the upper part of the bridge and carry positive current; thyristors 2,4 , and 6 which form the

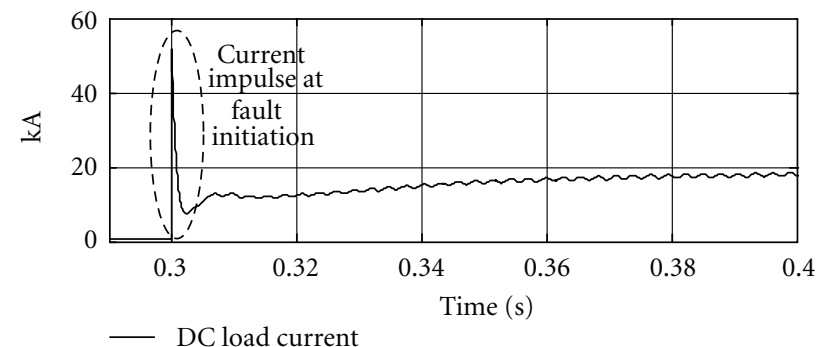

(a)

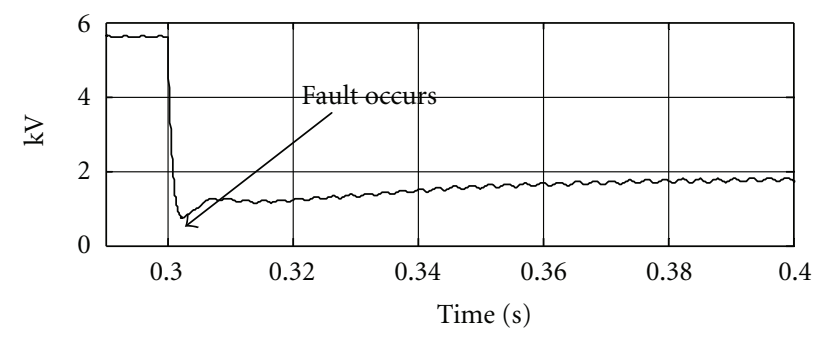

- DC bus voltage

(b)

Figure 5: Fault voltage and current profile for circuit shown in Figure 4(a).

lower part of the bridge and carry negative current. On the DC side there is a second order DC filter composed of $L_{d c}$ and $C$ with a series resistor $R_{d c}$ and a DC resistive load, $R_{\text {load. }}$. All the circuit parameter values are the same as those used in Section 4. As the load is varied from light load to short-circuit conditions the six-pulse rectifier exhibits three different forms of switching pattern due to the action of AC inductor $L_{c}$. For a cycle of sinusoidal AC input voltage the rectifier exhibits six switching intervals. These six switching intervals are identical in terms of the number of conducting switches in the upper and lower half of the bridge and each interval lasts $60 \circ$. Depending upon the number of diodes that conduct simultaneously during a switching interval, the rectifier would operate in mode 1 , mode 2 , or mode 3 [27-31].

The different modes are explained with the help of Figure 6 which shows the changes in the firing and overlap angles for a slow drop in DC load resistance. In mode 1 operation, not more than three diodes conduct at any point of time and the overlap angle $\mu$ always stays below $60^{\circ}$. This is because it is not possible for the overlap angle to increase smoothly without an increase in the firing angle $\alpha$. This gives rise to a separate operation mode, mode 2 , as shown in Figure 6. In mode 2, the firing angle increases for the increase in DC load current while the overlap angle stays constant at $60^{\circ}$. This change happens automatically without any change in the firing signals of the thyristors and is called an autophase control. In mode 2 , three diodes conduct during a switching cycle. In mode 3 , three and four diodes conduct during a switching cycle and the overlap angle is always between $60^{\circ}$ and $120^{\circ}$.

Various mathematical models of power electronic devices and circuits are used of simulation purposes. Detailed switch models available in simulation software are the most 


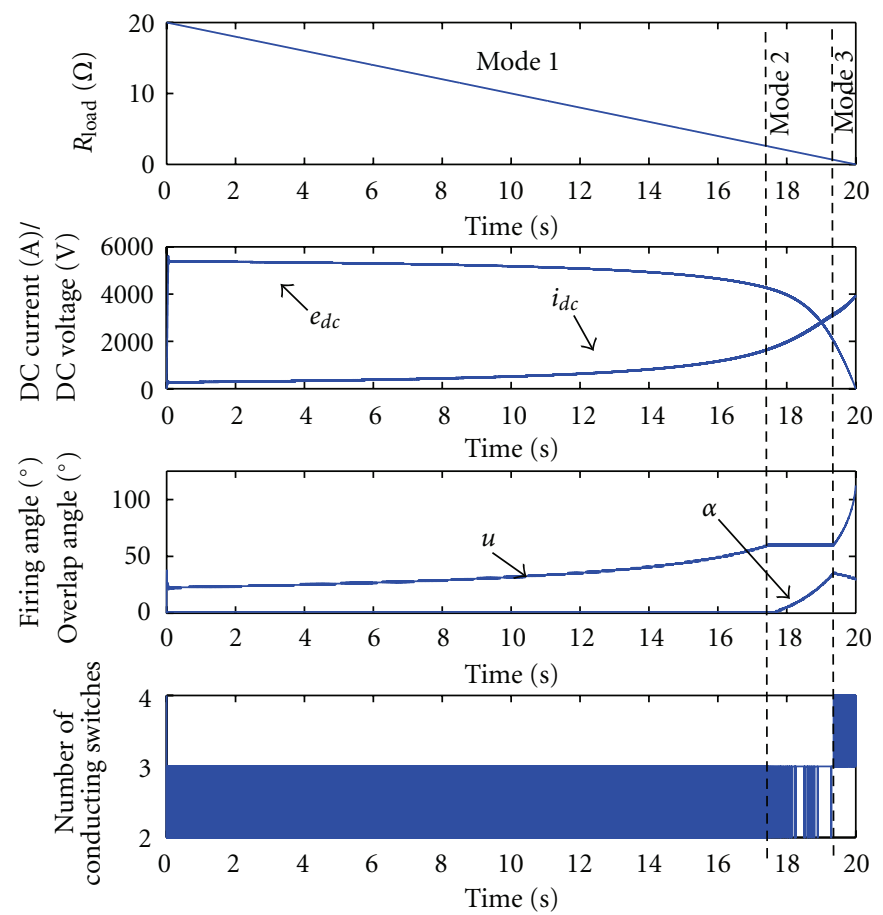

FIGURE 6: Firing angle $\alpha$, overlap Angle $\mu$, DC voltage $e_{d c}$, and current $i_{d c}$ for decreasing load resistance $R_{\text {load }}$.

TABLE 3: Quantities for mode 1 operation of rectifier.

\begin{tabular}{lc}
\hline $\begin{array}{l}\text { Conduction } \\
\text { pattern }\end{array}$ & 2 to 3 switches \\
\hline$\alpha\left(^{\circ}\right)$ & 0 \\
$\mu$ (radian) & $-\alpha+\arccos \left(\cos (\alpha)-\frac{2 \omega L_{c} i_{d c 0}}{\sqrt{3} E_{m}}\right)$ \\
$\bar{V}_{d c}(t)$ & $\frac{3 \sqrt{3} E_{m}}{\pi} \cos (\alpha)-i_{d c 0}\left(\frac{3 \omega L_{c}}{\pi}\right)-L_{c} \frac{d \bar{i}_{d c}}{d t}\left(2-\frac{3 u}{2 \pi}\right)$ \\
$\frac{d \bar{i}_{d c}}{d t}$ & $\frac{\left(3 \sqrt{3} E_{m} / \pi\right) \cos (\alpha)-i_{d c 0}\left(R_{d c}+3 \omega L_{c} / \pi\right)-e_{d c}}{L_{d c}+L_{c}(2-3 u / 2 \pi)}$ \\
\hline
\end{tabular}

accurate. The detailed switch model of the circuit shown in Figure 4(a) is developed in PSCAD/EMTDC. However, such models are very tedious and simulations using them take a long time to run. On the other hand, average value models (AVM) for power electronic converters are derived by averaging state variables in a circuit, like inductor current and capacitor voltage over one switching interval of the power converter operation [29, 30]. AVMs are more accurate than steady state models; however, they require the knowledge of the rectifier mode of operation. Additionally, AVMs are applicable in limited range of parameter values, like $L$ and $C$. The operation of rectifiers in mode 1 has been studied extensively since it is the normal mode of operation for six-pulse rectifiers feeding DC loads. An average value model is developed in $[27,28]$ for mode 1 . Novel average value models for modes 2 and 3 are developed in [31]. Due to the assumptions taken in the AVM approach, these models are applicable only for rectifiers with high filter inductance
TABLE 4: Quantities for mode 2 operation of rectifier.

\begin{tabular}{lc}
\hline $\begin{array}{l}\text { Conduction } \\
\text { pattern }\end{array}$ & 3 switches \\
\hline$\alpha\left(^{\circ}\right)$ & $\frac{\pi}{3}-\arccos \left(\frac{2 \omega L_{c} i_{d c 0}}{\sqrt{3} E_{m}}\right)$ \\
$\mu$ (radian) & $\pi / 3$ \\
$\bar{V}_{d c}(t)$ & $\frac{3 \sqrt{3} E_{m}}{\pi} \cos (\alpha)-i_{d c 0}\left(\frac{3 \omega L_{c}}{\pi}\right)-L_{c} \frac{d \bar{i}_{d c}}{d t}\left(2-\frac{3 u}{2 \pi}\right)$ \\
$\frac{d \bar{i}_{d c}}{d t}$ & $\frac{\left(3 \sqrt{3} E_{m} / \pi\right) \cos (\alpha)-i_{d c 0}\left(R_{d c}+3 \omega L_{c} / \pi\right)-e_{d c}}{L_{d c}+L_{c}(2-3 u / 2 \pi)}$ \\
\hline
\end{tabular}

in case of large signal studies. In this paper, we analyze the rectifier in mode 1 operation. The equations used to describe the operation of a rectifier in mode 1 , mode 2 , and mode 3 are presented in Tables 3, 4, and 5, respectively.

In the following sections the proposed fault interruption scheme is explained using the AVM as well as the detailed switch model.

\section{Fault Interruption Using Firing Angle Control}

In Section 4 it was stated that firing angle control can be used to bring the fault current to zero. A detailed analysis of this method for the fault shown in Figure 4(a) is given here. Note that a fault with a resistance of $0.1 \Omega$ was simulated using PSCAD/EMTDC at the terminals of the rectifier at $0.3 \mathrm{~s}$. The fault current and the DC voltage profile are shown in Figure 7. The fault is detected at $0.315 \mathrm{~s}$ and the firing angle of the rectifier $(\alpha)$ is set to $90^{\circ}$. This delay of $0.15 \mathrm{~s}$ 


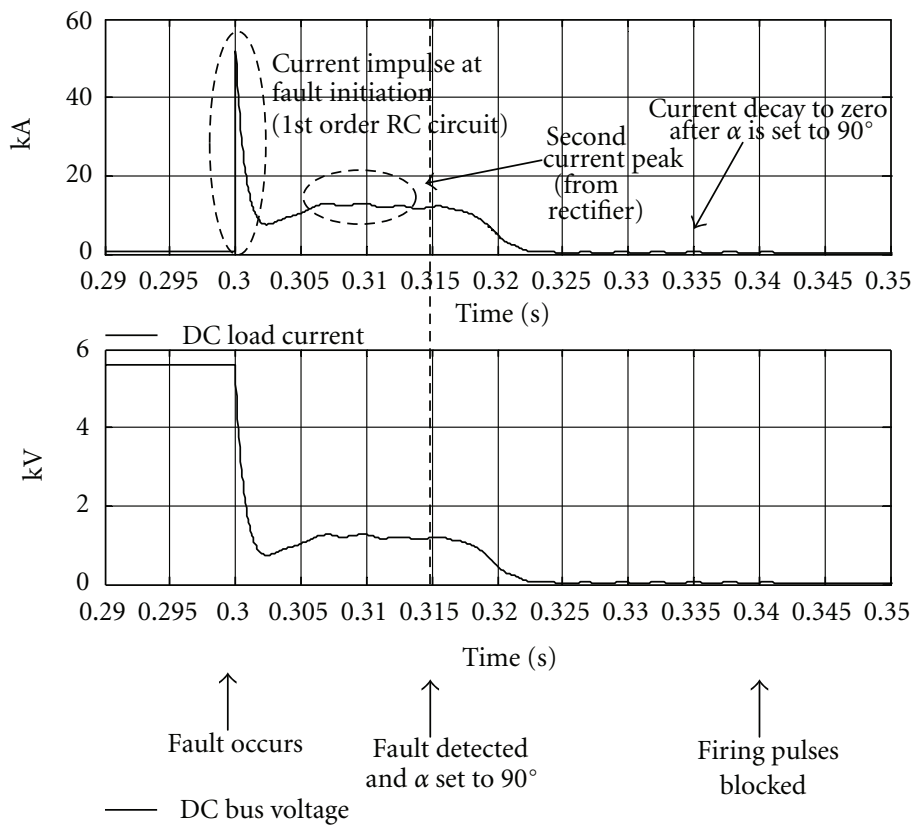

FIgURE 7: Fault interruption using firing angle control.

has been added to represent typical detection and reaction times. The current decays after few milliseconds and then the firing pulses are blocked at $0.344 \mathrm{~s}$, when the rectifier operates in the discontinuous conduction mode. Current interruption from the time of fault inception using the above method of firing angle control, without any circuit breaker, is approximately $0.344 \mathrm{~s}-0.300 \mathrm{~s}=44 \mathrm{~ms}$.

The rationale behind setting the firing angle control is explained as follows. The DC voltage from the rectifier $V_{d c}$ during continuous conduction is dependent upon the firing angle, $\alpha$ (see (3)). At firing angle of $90^{\circ}$, the rectifier internal voltage drops to zero. This technique can be used to force the rectifier to operate in discontinuous conduction mode after a high fault current event. Even though the rectifier internal voltage is negative above $\alpha=90^{\circ}$, the firing angle is set to $90^{\circ}$ to avoid any misfiring of thyristors which may cause unwanted transients.

The fault current seen in Figure 7 is contributed from two sources, namely, DC filter capacitor, and rectifier and is explained in detail below.

6.1. Fault Current from Filter Capacitor. The DC filter capacitor is charged to $V_{c}(0)=5.62 \mathrm{kV}$ during normal load operations. During the fault it discharges through the fault resistance, $R_{f}=0.1 \Omega$. Since this current path has a very low series inductance, it is idealized to be zero. The resulting circuit is a series $R C$ circuit and hence the fault current rises immediately to a peak of $V_{c}(0) / R_{f}=56 \mathrm{kA}$. This current decays over time and can be represented using the RC circuit transients as follows:

$$
I_{f}(t)=\frac{V_{c}(0)}{R_{f}} e^{-t / \tau},
$$

where, time constant $\tau=R_{f} \cdot C=0.1 \Omega \times 8 \mathrm{mF}=0.8 \mathrm{~ms}$. The theoretical results obtained using (2) are compared in
TABle 5: Quantities for mode 3 operation of rectifier.

\begin{tabular}{lc}
$\begin{array}{lc}\text { Conduction } \\
\text { pattern }\end{array}$ & 3 to 4 switches \\
\hline$\alpha\left(^{\circ}\right)$ & Variable \\
$\mu$ (radian) & $\arccos \left(\cos \left(\frac{\pi}{6}-\alpha\right)-\frac{2 \omega L_{c}}{E_{m}} i_{d c 0}\right)-\alpha-\frac{\pi}{6}$ \\
$\bar{V}_{d c}(t)$ & $\frac{9 E_{m}}{\pi} \sin \left(\alpha+\frac{\pi}{3}\right)-\frac{9 \omega L_{c}}{\pi} i_{d c 0}+\frac{9 \omega L_{c}}{2 \pi}\left(\alpha-\delta+\frac{2 \pi}{3}\right)$ \\
$\frac{d \bar{i}_{d c}}{d t}$ & $\frac{\left(9 E_{m} / \pi\right) \sin (\alpha+\pi / 3)-i_{d c 0}\left(R_{d c}+9 \omega L_{c} / \pi\right)-e_{d c}}{L_{d c}+L_{c}(3-9 u / 2 \pi)}$ \\
\hline
\end{tabular}

Figure 8(a) with those from the switch model shown in Figure 7. The fault current peak estimate from the theoretical model is accurate and the current decay is followed up to $0.301 \mathrm{~s}$, after which the fault current contribution from the rectifier becomes appreciable. At the same time, the capacitor voltage decays to fault voltage.

6.2. Fault Current Contribution from Rectifier. The second peak of the fault current in Figure 7 is due to the rectifier feeding current into the fault. To represent the rectifier in a simplified form, the mode $1 \mathrm{DC}$ average value model given in Table 3 has been used. $E_{m}$ is the peak line to neutral voltage, $L_{c}$ is the AC inductance, and $L_{d c}$ is the DC inductance. The differential equation is represented in equivalent circuit form in Figure 9, where, the voltage of the controlled DC source is given by

$$
V_{d}=\frac{3 \sqrt{3}}{\pi} \cos (\alpha) E_{m}=5.62 \cos (\alpha) \mathrm{kV} .
$$




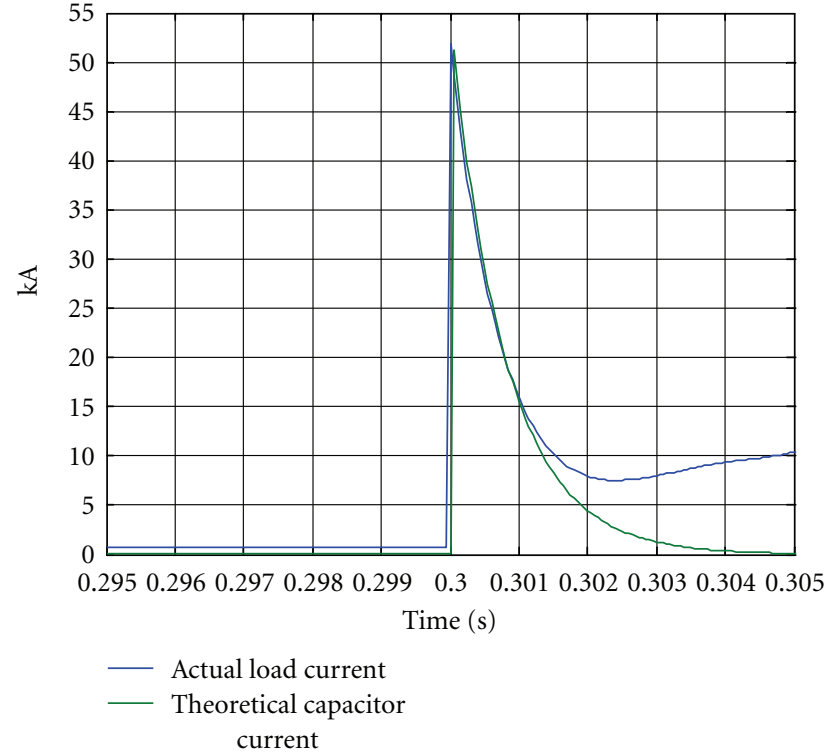

(a) Contribution from filter capacitor

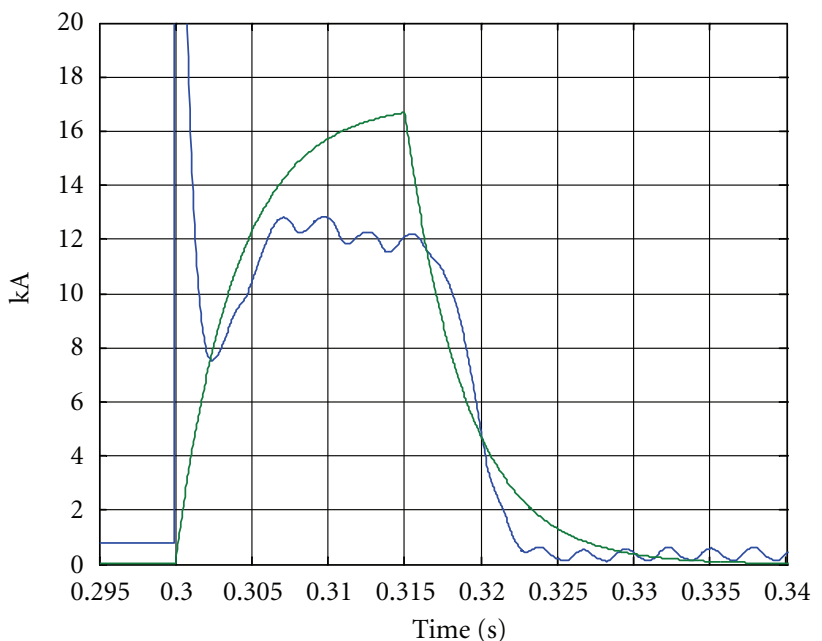

Actual load current
Theoretical rectifier
current

(b) Contribution from rectifier

FIGURE 8: Comparison of theoretical and actual fault current contributions.

The equivalent DC series resistor is given by (4), while the equivalent DC inductor is given by (5), as follows:

$$
\begin{gathered}
r_{d}=\frac{3}{\pi} \omega L_{c}=0.229 \Omega, \\
l_{d}=L_{d c}+2 L_{c}=0.0013 \mathrm{H} .
\end{gathered}
$$

Since the capacitor circuit has a faster time constant than the rectifier circuit, the peak from the capacitor precedes the peak of the fault current from the rectifier. The fault current profiles obtained using the analytical model and that from the PSCAD/EMTDC switch model are shown in Figure 8(b).

To keep the analytical model simple, only mode 1 operation of the rectifier has been considered. The error

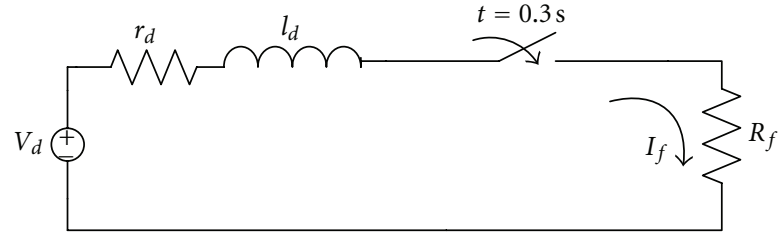

FIGURE 9: Equivalent circuit for fault current contribution from rectifier.

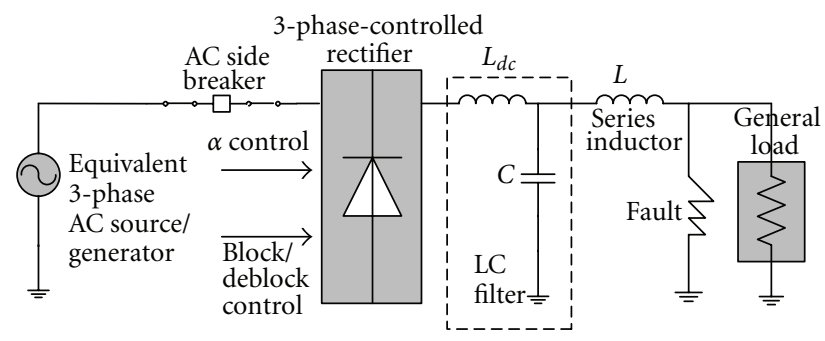

FIgURE 10: Controlled Rectifier with Series Inductor.

between the analytical model and switch model fault currents becomes maximum at high fault currents (see Figure 8(b)). Additionally, the rectifier is line commutated and has uncontrolled turn off time. Hence changing the firing angle to $90^{\circ}$ affects the fault current only during the next switching cycle. This delaying effect is evident from the results (see Figure 8(b)) obtained from the analytical model which responds instantaneously as compared to the detailed switch model in PSCAD/EMTDC.

The following section explains the proposed use of the series inductor to mitigate the fault current impulse and induce oscillations in the fault current.

\section{Fault Current Interruption with Series Inductor}

A controlled rectifier with a reactor inserted in series with the LC filter is shown in Figure 10. The three-phase AC source as well as the rectifier and filter components are the same as those used in Figure 4(a). The series inductor has been added to reduce the peak magnitude of the transient fault current shown in Figure 7 and also induce oscillations with zero crossings in the fault current. A detailed discussion on the selection criteria for the series inductor value is given in Section 9. An inductance value of $1 \mathrm{mH}$ is chosen in this example to limit the magnitude of the transient fault current to less than $15 \mathrm{kA}$.

The current and voltage profile of the DC bus in Figure 10 under load and fault conditions is shown in Figure 11. The DC bus supplies a $5.62 \mathrm{kV}$ DC voltage to the load until $0.3 \mathrm{~s}$. At $0.3 \mathrm{~s}$, a fault with resistance of $0.1 \Omega$ occurs across the DC bus. The fault current from the rectifier and the capacitor increases initially. Since, the series inductor and the filter capacitor form an underdamped loop, the capacitor current is oscillatory after the initial rise. At the same time, the rectifier current keeps rising to the steady state value. Similar to the previous case, the fault is detected at $0.315 \mathrm{~s}$ 

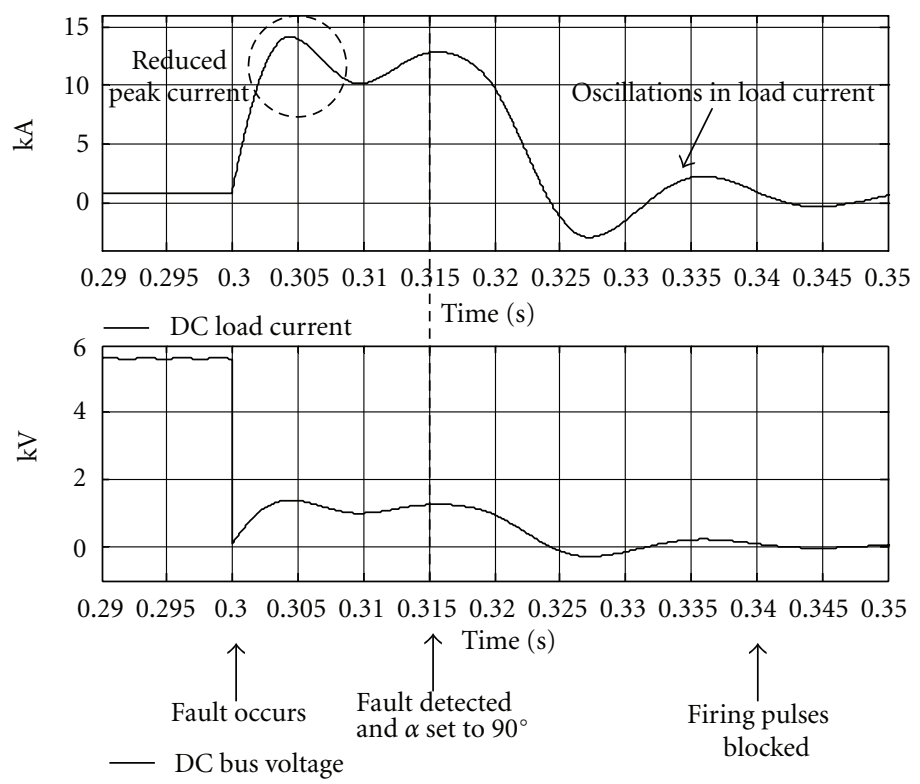

FIgURE 11: Effect of inserting series reactor on fault current and voltage.

and the firing angle of the rectifier is set to $90^{\circ}$. The fault current from the rectifier starts decaying after a small delay. During this decay, the fault current has several zero crossings; for instance the first zero crossings occurs at $0.325 \mathrm{~s}$ as seen in Figure 11. The rectifier current, which keeps decreasing slowly with time, can be interrupted by blocking the firing pulses after the rectifier goes into discontinuous conduction mode (DCM). The fault current profile has been analytically modeled using two circuit models, namely, the second order series RLC circuit model and the third order rectifier and filter circuit model.

7.1. Second Order RLC Circuit Model. After the fault occurs, the filter capacitor, which is charged to nominal DC bus voltage, discharges into the fault through the series inductor. The capacitor current contributes the major share of the fault current through the series inductor during the initial few milliseconds, when the rectifier current is negligible ( 0.3 to $0.305 \mathrm{~s}$ ) and also after the decay of rectifier current (after $0.32 \mathrm{~s})$. This can be seen in Figure 11. During those periods, the filter capacitor $C=8 \mathrm{mF}$, series reactor $L=1 \mathrm{mH}$, and fault resistance $R_{f}=0.1 \Omega$ form a second order series RLC circuit. The current in the circuit can be expressed using the second order differential equation with the solution given in

$$
I_{f}(t)=B_{1} e^{-\alpha t} \cos \left(\omega_{d} t\right)+B_{2} e^{-\alpha t} \sin \left(\omega_{d} t\right),
$$

where, damping coefficient $\alpha=R_{f} / 2 L=50$ nepers $/ \mathrm{sec}$, natural frequency $\omega_{0}=1 / \sqrt{L C}=353.535 \mathrm{rad} / \mathrm{sec}$ or $56.27 \mathrm{~Hz}$, and damping ratio $\eta=\alpha / \omega_{0}=0.141$. Since $\eta<1$, the system is underdamped, with damped frequency, $\omega_{d}=\sqrt{\left(\omega_{o}^{2}-\alpha^{2}\right)}=$ $350 \mathrm{rad} / \mathrm{sec}$ or $55.7 \mathrm{~Hz}$. $B_{1}$ and $B_{2}$ can be derived from the initial conditions for the capacitor voltage, $V_{c}(0)=5.62 \mathrm{kV}$, and the inductor current, $I_{f}(0)=0 \mathrm{~A}$, one has

$$
\begin{gathered}
B_{1}=0, \\
B_{2}=\frac{V_{c}(0)}{L \omega_{d}}=16.11 .
\end{gathered}
$$

Substituting (7) in (6) yields

$$
I_{f}(t)=16.11 e^{-50 t} \sin (350 t)
$$

The peak time and peak current using (8) are calculated in

$$
\begin{gathered}
t_{\text {peak }}=\frac{\pi}{2 \omega_{d}}=0.00448 \mathrm{sec}, \\
I_{f \text {,peak }}=I_{f}\left(t_{t}=t, \text { peak }\right)=12.78 \mathrm{kA} .
\end{gathered}
$$

7.2. Third Order Equivalent Circuit Model. The accuracy of the results obtained in the previous subsection can be improved by adding an equivalent rectifier circuit model described in Section 6 in parallel with the second order RLC circuit. This results in a third order equivalent circuit. The results of the second order and third order equivalent circuit models are compared with those from the detailed switch model in Figure 12.

7.3. Comparison of Models. Both the second and third order models track the rising portion of the fault current up to the first peak. The time constant of the rising portion can therefore be derived with sufficient accuracy using the second order differential equation solution given in (8). After the first peak, the rectifier current forms an appreciable portion of the inductor current; therefore the second order solution does not track the fault current. Whereas, the third order 


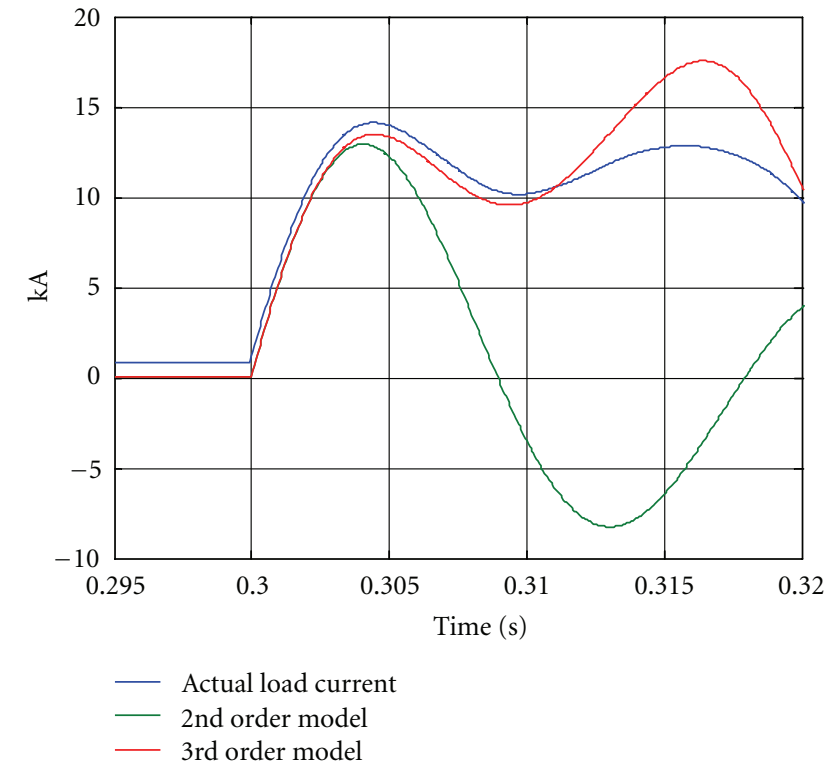

Figure 12: Comparison of fault current profiles from various models.

model which also includes the rectifier model follows the fault current, approximately, after the first peak.

The third order model overestimates the second peak from the rectifier current because it is applicable only in mode 1 operation. After $0.315 \mathrm{~s}$ the firing angle is changed to $90^{\circ}$ and the rectifier now operates in mode 2 and then mode 3 . Since the rectifier is line commutated with uncontrolled turn off switches, the commanded firing angle takes about one switching cycle to affect the DC fault current. This explains the delay in the start of current decay after $0.315 \mathrm{~s}$. During the decay, the third order model describes the rate of fall in the fault current accurately until the rectifier operates in continuous conduction mode (CCM). The accuracy of the mode 1 model is sufficient for quantifying the rate of rise and estimating the peak fault current. A comparison of both models is given in Table 6 .

\section{Fault Current Interruption Using AC Circuit Breakers}

In Section 7, it was seen that the impulse current from the capacitor can be mitigated by adding a series inductor in the fault current path. However, by adding the inductor, the fault current does not go to zero, after blocking the firing pulses of the rectifier due to oscillations in the fault current. These oscillations after $0.32 \mathrm{~s}$ are shown in Figure 11. This high oscillatory current can be damaging to the capacitor, the DC bus, and transmission cables. Hence, this current has to be interrupted as soon as the rectifier current reduces below the load current. The oscillatory nature of this current can itself be exploited to interrupt the current using a conventional AC circuit breaker.

The rectifier schematic with the AC circuit breaker is shown in Figure 13. The fault current interruption for this circuit is shown in Figure 14. In this interruption technique
TABLE 6: Comparison of circuit models.

\begin{tabular}{lccc}
\hline Model & $\begin{array}{c}\text { Detailed switch } \\
\text { (PSCAD) }\end{array}$ & $\begin{array}{c}\text { 2nd order } \\
\text { series RLC }\end{array}$ & $\begin{array}{c}\text { 3rd order rectifier } \\
\text { and filter equiv. }\end{array}$ \\
\hline $\begin{array}{l}t_{\text {peak }}(\mathrm{s}) \\
\begin{array}{l}\text { Peak magnitude } \\
(\mathrm{kA})\end{array}\end{array}$ & 0.0044 & 0.0044 & 0.0044 \\
\hline
\end{tabular}

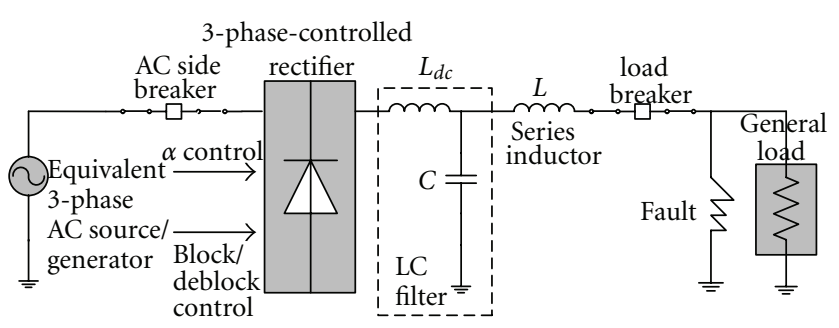

Figure 13: Controlled rectifier with series inductor and AC breaker.

the circuit breaker is set to trip as soon as firing angle is set to $90^{\circ}$ at $0.315 \mathrm{~s}$. Since the fault current has the first zero crossing at $0.325 \mathrm{~s}$, the AC circuit breaker interrupts the fault current at this instant. The circuit breaker remains open after $0.325 \mathrm{~s}$, if the recovery voltage across it does not cause any dielectric breakdown.

The fault current can be interrupted faster before the occurrence of the second peak by sending the breaker trip signal and firing angle command before $0.315 \mathrm{~s}$. The results of the faster fault current interruption scheme are shown in Figure 15. The trip signal and firing angle command are sent when the DC fault current exceeds $5 \mathrm{kA}$ which happens before the first peak. Since the first peak of the fault current is a result of the capacitor discharge, its magnitude is not affected by the firing angle setting of the rectifier. However, the rectifier current is interrupted before reaching its peak. The RLC oscillation causes a zero crossing after the first peak at $0.3094 \mathrm{~s}$; the fault current is interrupted at this instant using the AC breaker.

\section{Criteria for Selection of Series Inductor}

In Section 7, a $1 \mathrm{mH}$ inductor was added in series with the output filter to limit the magnitude of the DC fault current and induce current oscillations with zero crossings. This section formalizes the rules for selecting an appropriate value of the series inductor. The rules are explained below.

(i) The primary criterion for selection of the value of the series inductor is that it must limit the fault current to the desired value. An estimate of the peak fault current magnitude can be obtained by using the circuit models developed in Section 7. The third order model is more accurate than the second order model because it takes the rectifier dynamics into account. A plot of peak fault current magnitudes versus inductor values for various fault resistances is shown in Figure 16(a). Note that other circuit parameters, like the rectifier input voltage, filter capacitor, and inductor, are the same as those used 

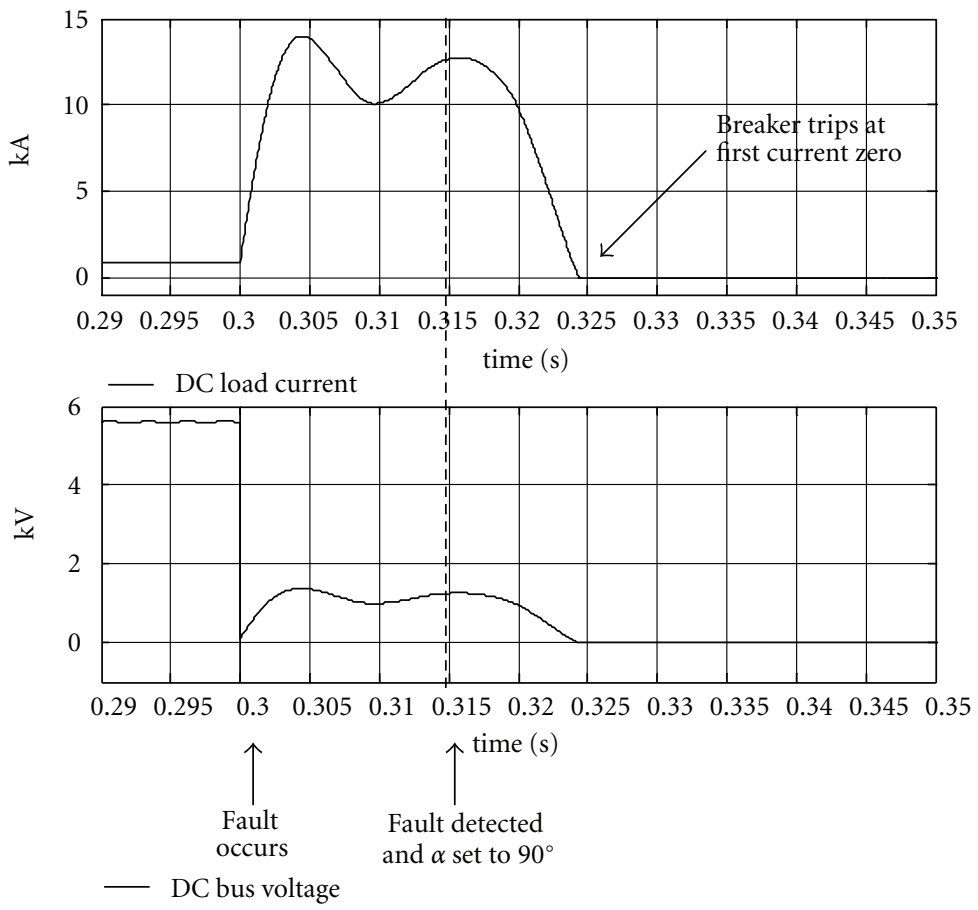

FIGURE 14: Fast fault current interruption using AC circuit breaker.

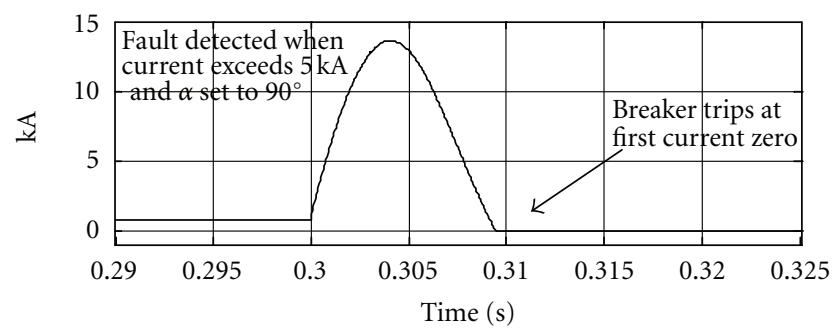

— DC load current

(a)

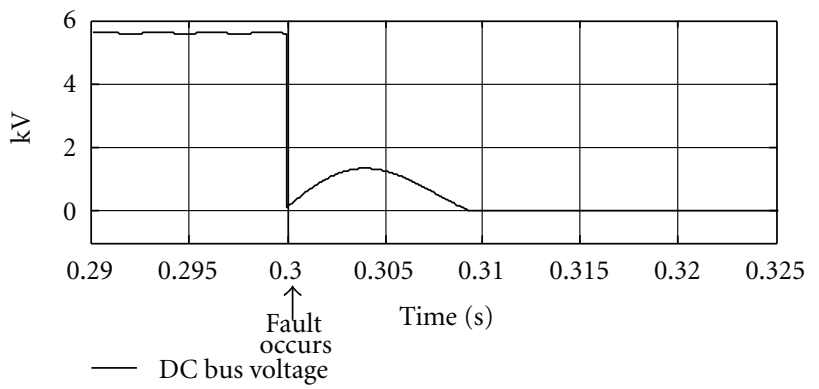

(b)

FIGURE 15: Fault current interruption with fault detect at $5 \mathrm{kA}$.

throughout the paper. The plot will change with the values of these parameters.

(ii) For the second criteria, the filter capacitor, series inductor, and fault resistor must form an underdamped loop (damping ratio $\eta<1$ ). Only when this criterion is satisfied will there be oscillations in the fault current. A plot of $\eta$ versus inductor values for various values of the fault resistance is shown in Figure 16(b). Other circuit parameters are the same as those used throughout the paper.

Referring to the plots in Figures 16(a) and 16(b) for a series inductor value of $1 \mathrm{mH}$ chosen previously, the peak magnitude of the fault current is around $14 \mathrm{kA}$, while the value of $\eta$ is 0.14 . These values match those obtained using the detailed switch model in Section 7. The value of $\eta$ and the peak fault current magnitude can be used to set the firing angle and the circuit breaker controls.

The value of the series inductor is chosen by utilizing the plots in Figures 16(a) and 16(b). However, the plots are themselves based on different values of the fault resistance, $R_{f}$, which will be unknown before the fault actually occurs, in most cases. Hence, before applying these criteria for the selection of series inductor, one must define the fault current threshold. Utilizing this fault current threshold magnitude as well other component values, the corresponding value of the fault resistance, $R_{f}$, can be computed. Once $R_{f}$ is known, Figures 16(a) and 16(b) can be easily applied to find the appropriate series inductor value.

\section{Conclusion}

This paper developed an innovative DC fault interruption technique using a series reactor and a conventional $\mathrm{AC}$ circuit breaker. It is applicable to MVDC system architectures in distribution systems of electric ships and electric vehicles. Before describing the proposed approach a review of the state-of-the-art DC fault interruption techniques was provided and their shortcomings were pointed out. In the 


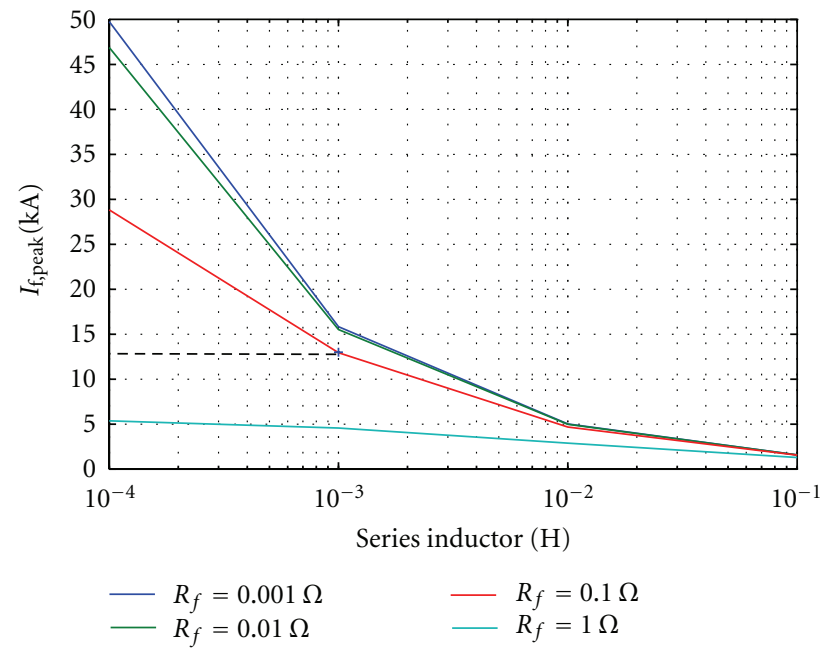

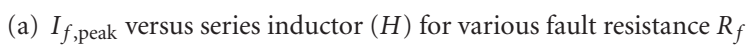

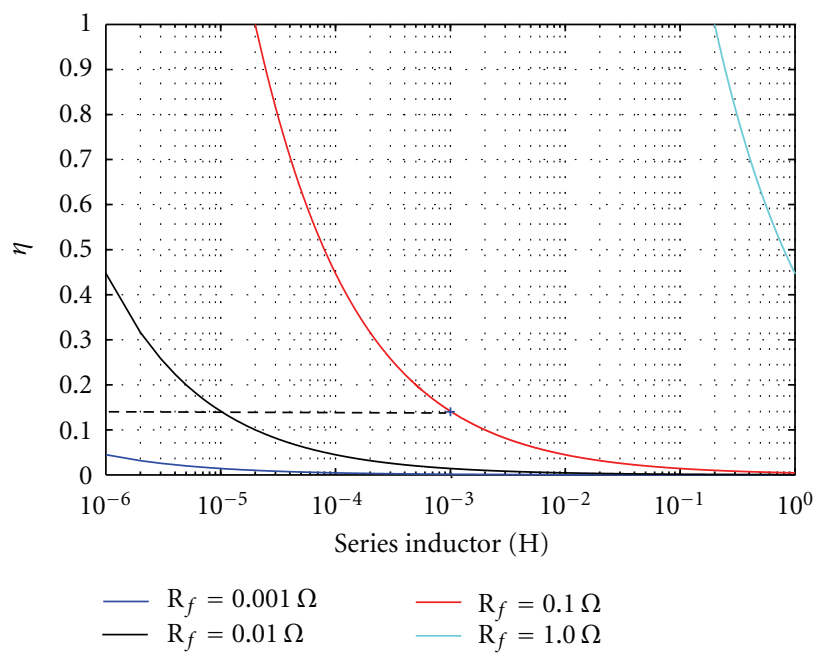

(b) $\eta$ versus series inductor $(H)$ for various fault resistance $R_{f}$

FIGURE 16: Criteria for selection of series inductor.

next step, the fault current characteristics of a controlled rectifier with LC filter were studied using analytical average value models as well as detailed switch models developed in PSCAD/EMTDC. The fault current was found to be contributed from two components, namely, the filter capacitor and the rectifier. For a fault at the terminals of the rectifier, the capacitor discharge causes a damaging impulse current to flow through the circuit. Controlling only the firing of the thyristors the fault current was brought to zero in $44 \mathrm{~ms}$ as shown in Figure 17. The paper then proposed to use a series inductor to limit the magnitude of the fault current impulse. Furthermore, the series inductor causes oscillations in the fault current due to underdamped series RLC configuration of the resulting circuit. In the next step, it was proposed to exploit the resulting zero crossings in the fault current for faster interruption. A conventional AC circuit breaker was used for this task and the fault was interrupted at the first zero crossing, $25 \mathrm{~ms}$ after its inception as shown in Figure 17. The fault current interruption time was shown to be greatly

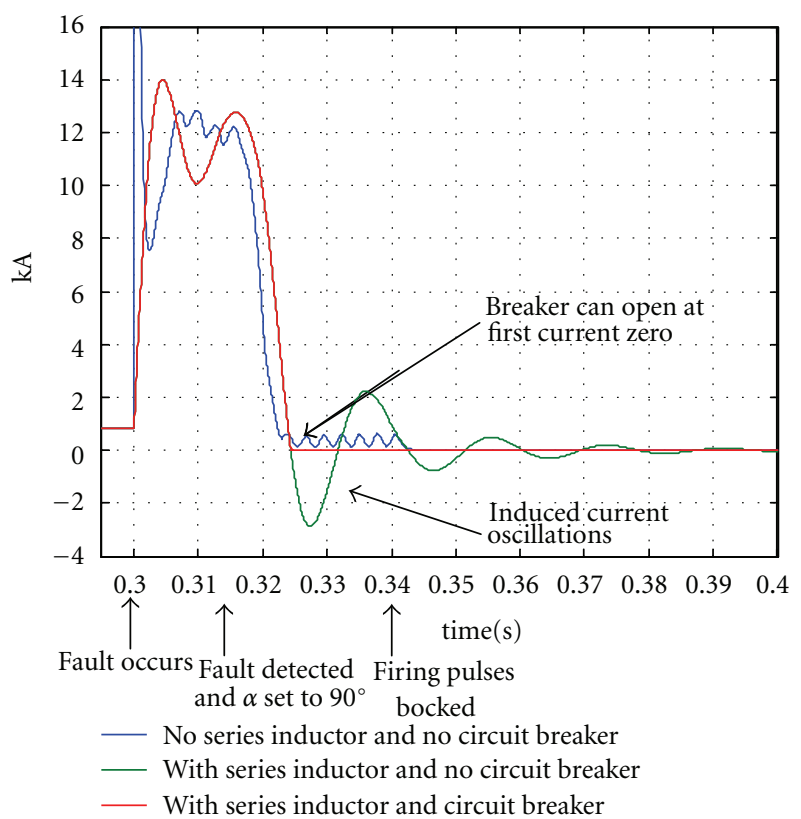

Figure 17: Comparison of fault interruption using different methods.

reduced to about $9 \mathrm{~ms}$ by using simple current detection scheme for the reactor assisted circuit breaker.

One of the limitations of the proposed method includes the trade-off between the reduction in fault current magnitude and fault interruption time. A series inductor of a larger value will be able to limit the fault current to a lower magnitude; however, the fault interruption time will be increased. Additionally, the proposed DC fault interruption method is best suited for shunt faults with low fault impedance values. High impedance faults will require very large series inductor values to produce oscillations in the fault current, which will increase the fault interruption time. This will also result in significant losses in the inductor during normal unfaulted operation.

In this way, the proposed fault interruption scheme is simple with its use of an AC circuit breaker, fast because the fault can be cleared sooner than using firing angle control alone and efficient because it lowers the risk of damage to the rest of the system components by isolating the faulted section.

\section{Acknowledgments}

This work has been supported in part by the Office of Naval Research under the Electric Ship Research and Development Consortium. The authors also thank Mr. Pandarinath Murali for his assistance.

\section{References}

[1] "Next generation integrated power system: NGIPS technology development roadmap," Tech. Rep., Naval Sea Systems Command, Washington, DC, USA, 2007.

[2] "IEEE recommended practice for $1 \mathrm{kV}$ to $35 \mathrm{kV}$ mediumvoltage dc power systems on ships," IEEE Std 1709-2010, pp. 1-54, 2010. 
[3] W. Grieshaber, "Dc circuit breakers: an important role in the continuity and quality of service," Tech. Rep., Areva's Think T \& D, 2010.

[4] C. Meyer, M. Kowal, and R. W. De Doncker, "Circuit breaker concepts for future high-power DC-applications," in Proceedings of the 40th IEEE Industry Application Society Annual Meeting (IAS '05), vol. 2, pp. 860-866, October 2005.

[5] L. Tang and B. T. Ooi, "Protection of VSC-multi-terminal HVDC against DC faults," in Proceedings of the IEEE 33rd Annual Power Electronics Specialists Conference (PESC'02), vol. 2, pp. 719-724, June 2002.

[6] F. Luo, J. Chen, X. Lin, Y. Kang, and S. Duan, "A novel solid state fault current limiter for DC power distribution network," in Proceedings of the 23rd Annual IEEE Applied Power Electronics Conference and Exposition (APEC '08), pp. 1284-1289, February 2008.

[7] Z. Xu, B. Zhang, S. Sirisukprasert, X. Zhou, and A. Q. Huang, "The emitter turn-off thyristor-based DC circuit breaker," in Proceedings of the IEEE Power Engineering Society Winter Meeting, vol. 1, pp. 288-293, January 2002.

[8] J. M. Meyer and A. Rufer, "A DC hybrid circuit breaker with ultra-fast contact opening and integrated gate-commutated thyristors (IGCTs)," IEEE Transactions on Power Delivery, vol. 21, no. 2, pp. 646-651, 2006.

[9] M. E. Baran and N. R. Mahajan, "Overcurrent protection on voltage-source-converter-based multiterminal DC distribution systems," IEEE Transactions on Power Delivery, vol. 22, no. 1, pp. 406-412, 2007.

[10] L. Tang and B. T. Ooi, "Locating and isolating DC faults in multi-terminal DC systems," IEEE Transactions on Power Delivery, vol. 22, no. 3, pp. 1877-1884, 2007.

[11] R. D. Garzon, High Voltage Circuit Breakers: Design and Applications, CRC Press, 2nd edition, 2002.

[12] M. Benouar, "Pyrotechnique circuit interrupter for the protection of electrical systems," IEEE Transactions on Power Apparatus and Systems, vol. 103, no. 8, pp. 2006-2010, 1984.

[13] K. A. Corzine and R. W. Ashton, "Structure and analysis of the Z-source MVDC breaker," in Proceedings of the 4th IEEE Electric Ship Technologies Symposium (ESTS '11), pp. 334-338, April 2011.

[14] K. A. Corzine and R. W. Ashton, "A new Z-source DC circuit breaker," IEEE Transactions on Power Electronics, vol. 27, no. 6, pp. 2796-2804, 2012.

[15] R. K. Smith, P. G. Slade, M. Sarkozi, E. J. Stacey, J. J. Bonk, and H. Mehta, "Solid state distribution current limiter and circuit breaker: application requirements and control strategies," IEEE Transactions on Power Delivery, vol. 8, no. 3, pp. 11551164, 1993.

[16] T. Jinzenji and T. Kudor, "Gto dc circuit breaker based on a single-chip microcomputer," IEEE Transactions on Industrial Electronics and Control Instrumentation, vol. 33, no. 2, pp. 138143, 1986.

[17] M. M. A. Salama, H. Temraz, A. Y. Chikhani, and M. A. Bayoumi, "Fault-current limiter with thyristor-controlled impedance (FCL-TCI)," IEEE Transactions on Power Delivery, vol. 8, no. 3, pp. 1518-1528, 1993.

[18] C. Meyer, M. Kowal, and R. W. De Doncker, "Circuit breaker concepts for future high-power DC-applications," in Proceedings of the IEEE Industry Application Society Annual Meeting (IAS '05), vol. 2, pp. 860-866, October 2005.

[19] J. Skindhøj, J. Glatz-Reichenbach, and R. Strümpler, "Repetitive current limiter based on polymer PTC resistor," IEEE Transactions on Power Delivery, vol. 13, no. 2, pp. 489-494, 1998.
[20] R. Strumpler, J. Skindhoj, J. Glatz-Reichenbach, J. H. W. Kuhlefelt, and F. Perdoncin, "Novel medium voltage fault current limiter based on polymer PTC resistors," IEEE Transactions on Power Delivery, vol. 14, no. 2, pp. 425-430, 1999.

[21] P. Tixador, Y. Brunet, J. Leveque, and V. D. Pham, "Hybrid superconducting AC fault current limiter principle and previous studies," IEEE Transactions on Magnetics, vol. 28, no. 1, pp. 446-449, 1992.

[22] A. M. S. Atmadji and J. G. J. Sloot, "Hybrid switching: a review of current literature," in Proceedings of the 2nd International Conference on Energy Management and Power Delivery (EMPD '98), vol. 2, pp. 683-688, March 1998.

[23] C. S. G. Asplund and V. Lescale, "Direct current breaker for high power for connection into a direct current carrying high voltage line," U.S. Patent 5,517,378, 1996.

[24] Gerapid high speed DC circuit breakers-on the move. GE Consumer and Industrial Electrical Distribution, http://www .geindustrial.com/cwc/electrical_homepage.htm.

[25] High-speed DC circuit-breakers for fixed installation. Secheron, http://www.secheron.com/data/classes/produit/.

[26] Dc switchgear for DC traction power supply. Siemens Sitras DSG, http://www.mobility.siemens.com/en/data/pdf/ts_el/ produkte/dsg_pi_112_76.pdf.

[27] P. Krause, O. Wasynczuk, S. Sudhoff, and I. P. E. Society, Analysis of Electric Machinery and Drive Systems, IEEE Press, 2002.

[28] S. Chiniforoosh, J. Jatskevich, V. Dinavahi et al., "Dynamic average modeling of line-commutated converters for power systems applications," in Proceedings of the IEEE Power and Energy Society General Meeting (PES '09), pp. 1-8, July 2009.

[29] H. Zhu, R. P. Burgos, F. Lacaux et al., "Average modeling of three-phase and nine-phase diode rectifiers with improved AC current and DC voltage dynamics," in Proceedings of the 31st Annual Conference of IEEE Industrial Electronics Society (IECON'05), pp. 1024-1029, November 2005.

[30] R. D. Middlebrook and S. Cuk, "A general unified approach to modelling switching-converter power stages," International Journal of Electronics, vol. 42, no. 6, pp. 521-550, 1977.

[31] P. Murali and S. Santoso, "Dynamic modeling of short-circuit behavior of a six-pulse rectifier," in Proceedings of the 4th IEEE Electric Ship Technologies Symposium (ESTS '11), pp. 486-491, April 2011. 

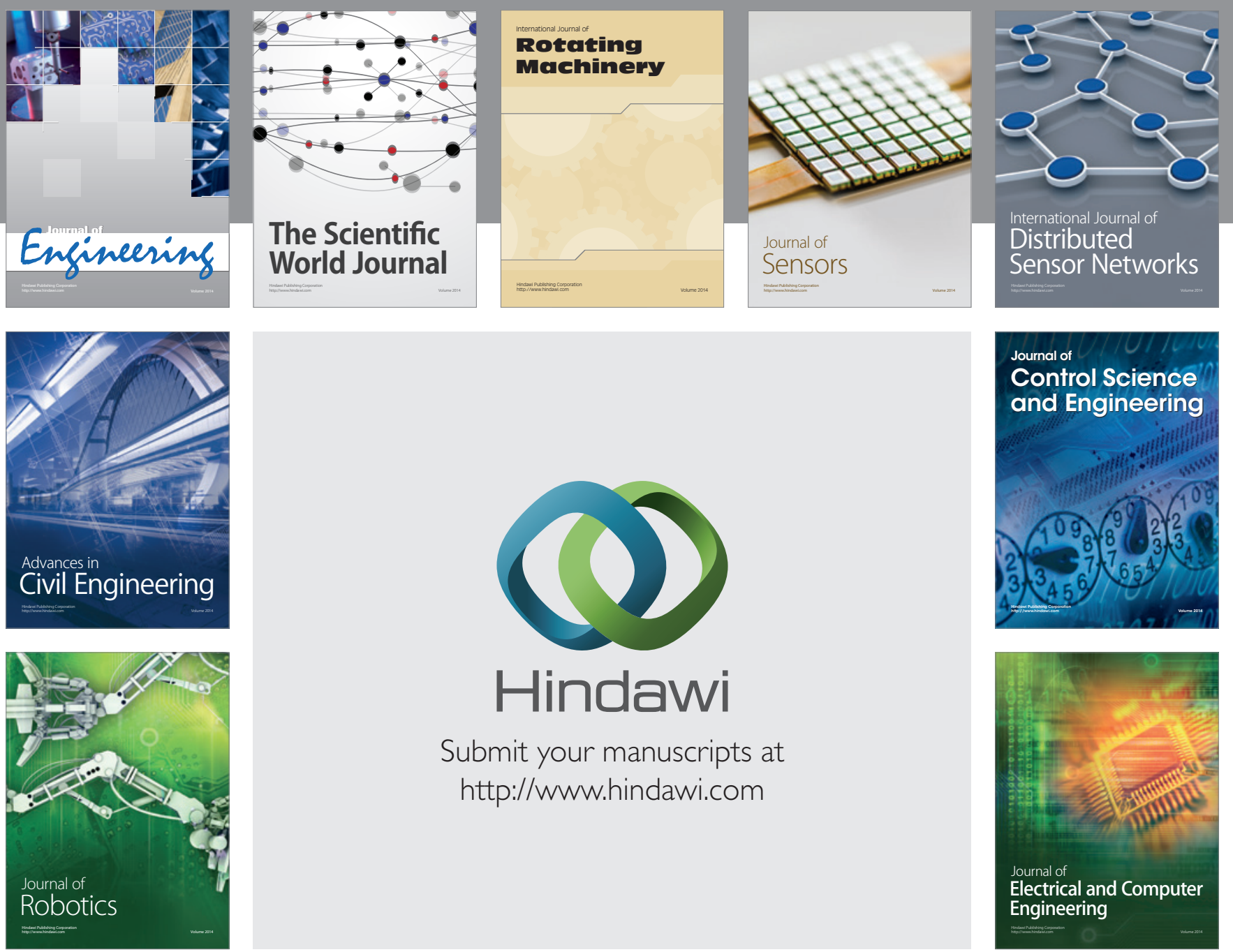

Submit your manuscripts at

http://www.hindawi.com
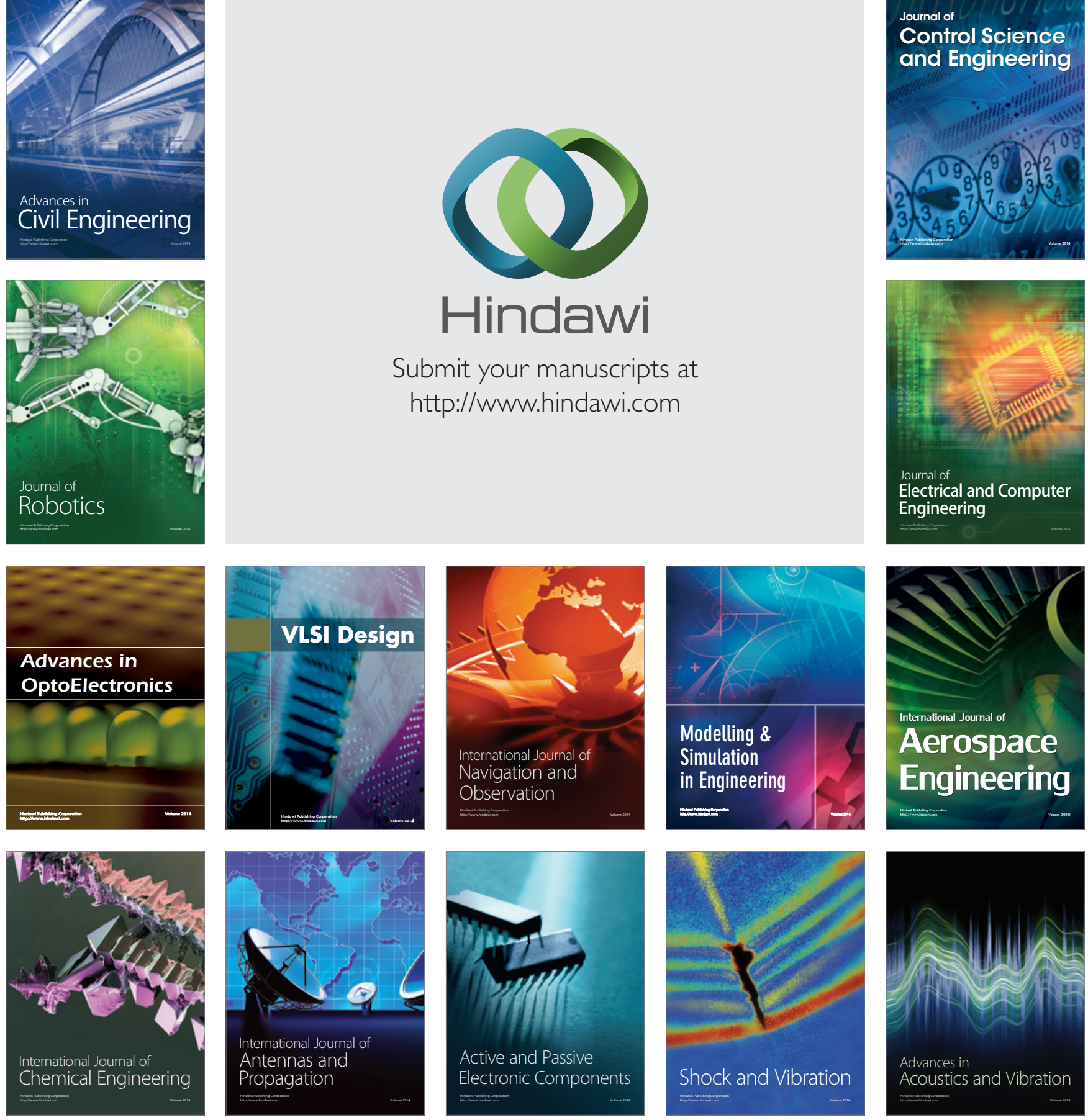